\title{
Dance and Disability: Embracing difference, tensions
}

\author{
and complexities
}

\author{
Sue Cheesman \\ The University of Waikato
}

\begin{abstract}
In this paper I am particularly interested in unpacking the notion that dancers with a visible disability are both marginalised and hyper-visible. I refer to selected dance examples available on YouTube and consider these in relation to Whatley's (2007) presumption of difference indicators in support of my aim to expand research into the area of dance and disability. Viewing these dance examples provided a 'bouncing off' point from which to unpack how these performances are perceived and made meaningful by their audiences. Drawing from discussion tasks set at several different conferences in response to viewing these dance examples, I share initial findings and consider issues that arose in embracing difference, tensions and complexities.
\end{abstract}

\section{Introduction}

Dancing Wheels, Axis, Joint Forces, Bill T Jones (USA), Amici, Common Ground, Candoco, DV8 (England) and Touch Compass (New Zealand) are some of the dance companies across three different continents working with a variety of individuals with different forms of embodiment. Over the last two decades these companies have pushed hard for change. They have helped pave the way by breaking new ground through challenging a dominant dance aesthetic and the 'legitimate' dancing body, allowing for the lens to be shifted towards a celebration of diversity and multiple possibilities. As noted by Benjamin (2010), these developments have also made possible for individual choreographers and performers with a disability to work with a range of different companies or independently outside of an integrated platform in the mainstream, as exemplified by the work of Marc Brew, David Toole and Claire Cunningham, to name a few.

The huge explosion and development of online media such as YouTube has seen these dance artists and companies offer their work as open source, free for anyone to view. The ramifications of this are that many more possibilities to freely view a range of dance performances, including performers with a range of different embodiments, has opened up. As a consequence I would suggest that, especially 
within research and education, online media provide a platform for viewing and responding to a much greater range of dance works.

Links to two dance examples I have selected for discussion are provided below. I offer the opportunity for the reader to engage with these preselected YouTube clips and thereby bring into play your own responses to content, issues and tensions raised in this article.

Task: Watch each clip separately and record your responses after viewing the clip using the following headings as guides: challenges, surprises, associations and meanings.

https://www.youtube.com/watch?v=mLe9ZSwU4aQ

http://www.youtube.com/watch?v=qi7KNDtpXJA

\section{Methodology}

Just as I have offered readers the opportunity to engage with these examples, the same online clips were presented to participants at several differently themed conferences. Prior to their viewing, I chose to give very little information about the dance or dancers apart from the names of the dancers and the title of piece. Each clip was showed separately and participants were given a sheet with the following headings: challenges, surprises, associations and meanings. Time was allowed for participants to record their responses.

Participants were then given a further sheet setting out the five 'presumption of difference' indicators developed by Whately (2007) and used with her students as a way of opening up dialogue around their responses. Whately explains:

It seems to be the case that a 'presumption of difference' calls on different, culturally inscribed viewing strategies, which lead to various interpretations and evaluations of the dance and which may themselves call for new ways of reflecting upon and writing about the dance.... I arrived at these strategies through the process of working with the students, discussing their responses to dance both in class and in performance, and exploring published views of others who view and participate in dance. I have identified five viewing strategies, which I have termed as follows: Passive Oppressive, Passive Conservative, PostPassive, Active Witness and Immersion. (p. 21) 
In the same vein, I offer you as a reader the following task.

Task: Before reading on I would encourage readers to unpack their own responses in relation to the five indicators below:

A 'Presumption of Difference': Strategies for Viewing expanded by Whately (2007, p. 22)

1. Passive Oppressive: Voyeur, Sense of 'otherness' , Fear of contagion , Interpretation is oppressive

2. Passive Conservative: Ablist gaze, Avoids confrontation, Interpretation is inappropriate (based on classical aesthetic)

3. Post-Passive: Looks for transcendence of disability, Discounts the disability , Interpretation is selective; disability is erased in judgement, Disrupts oppressive position

4. Active Witness: Active engagement with the dance, Disability is 'ordinary', Interpretation is open, allows for radical shift in aesthetic

5. Immersion: The 'how' not the 'what', Viewer experiences their own becoming through viewing, Active engagement, Interpretation is based on experience of own embodiment

The aim of this task in the conference context was to facilitate discussions among conference participants by unpacking their responses in relation to the presumption of difference indicators. Although it may be argued that this is only one way of viewing work, these strategies provided a framework post-viewing, allowing participants to place their responses within a continuum. The strategies provided a 'bouncing off point' to interrogate ideas raised and further discussion around responses to viewing those selected clips.

After initial discussions of the viewings in relation to Whatley (2007), I introduced the following questions to stimulate deeper thinking and raise debate around the tensions and complexities in describing this work.

- Are disability performers both marginalized and highly visible?

- How do all the dancers on the selected clips disrupt or reinforce your views on dance?

- How do dominant cultural norms affect what you see?

- How do we challenge our vested interests and assumptions? 


\section{Dance examples from YouTube}

The first example shown was "How to dance without legs", in which dancers David Toole and Tanja Liedtke perform an extract from The Cost of Living by DV8 Physical Theatre (Lloyd Newson, 2004). I made a deliberate decision not to contextualize this within the overall DV8 production and to instead focus on the duet only. My decision was partly based on seeing the production live in 2001-in writing a review I was at the time troubled by the use of two dancers capable of far more than the cameo roles this choreography placed them in (Cheesman, 2001).

The second dance example was To Color Me Different (2008). The work was choreographed Alex Ketley in collaboration with Axis Dance Company dancers Sonsherée Giles and Rodney Bell.

Both dance examples were choreographed rather than improvisational, artistic works in the contemporary dance genre, and showed performers with different forms of embodiment. Both were male-female duets with the male performers in each having a visible disability. Accomplished dancers David Toole and Tanja Liedtke perform the first duet. David Toole learnt his craft initially from 1992 with his years in Candoco. His duet partner is Tanja Liedtke, a choreographer and performer trained at Rambert School in London who has had several major roles in DV8 productions. Rodney Bell gained much of his dexterity in the wheelchair from being a 'wheelblack' playing wheel chair basketball to national standard in New Zealand and subsequently began his journey in dance with Touch Compass, before joining Axis. His duet partner, Sonsherée Giles, is a contemporary trained choreographer and dancer who joined Axis in 2005 and is now associate director of the company. She cites yoga and running as influences on her style (http: //axisdance.org/about-us/staff-board/).

\section{Contested terms, models and binaries}

Within the contemporary dance genre that this work is often placed, I would argue that there is a much wider range of body types performing than in classical dance genres. However, I still think there is a tendency for the prevailing image of performers in this genre to be seen as physical, muscular, flexible and lean. This is different to the ballet aesthetic but nevertheless, I would contest, can be as restricting and exclusionary. This certainly begs the question, how is a dancer who does not confirm to the 'dancer aesthetic' viewed? Petra Kuppers (2011) points out 
that "people with physical impairments are hyper visible, instantly defined by their physicality" (p. 25). Agreeing with this point Celeste Dandeker (2007), former artistic director of Candoco, reminds us that it is not the full picture. "We are not precious about disability-we are not trying to hide it, it is just part of the personit's not the whole thing" (p. 29). Ann Cooper Albright (2001) agrees by asserting that "watching disabled bodies dancing forces us to see watching with a double vision, and helps us to recognise that while a dance performance is grounded in the physical capacities of a dancer, it is not limited by them" (p. 58). Too often 'other' is seen as a threat to society. However it would be generally agreed that any attempts to define terms raises many political issues. I agree that disability is a deeply contested term (Benjamin, 2001; Cheesman, 2011; Kuppers, 2003; Whatley, 2007;). Perhaps, in order to put a dancer's individual experiences into context, "it is helpful to understand how society may view and label difference" (Irving \& Giles, 2011, p. 374).

The medical model places disability at the centre, abnormal and in need of fixing whereas the social model places disability within a society constructed for the able-bodied. "Disability is a disjuncture between the body and the environment" (Sandahl \& Auslander, 2005, p. 8) and within these terms, disability becomes a social and environmental issue, not a medical one (Kuppers, 2003). The previous models have been discussed extensively. However, new thinking by Kuppers (2011) proposes a rhizomatic model of disability located in the lived experience and embedded in Deleuzoguattarian concepts. "This model queries its own character as model, since its emergence is singular, specific and momentary," writes Kuppers. She explains further:

The rhizoid model of disability produces an abundance of meanings that do not juxtapose pain and pleasure or pride and shame but allow for an immanent transformation, a coming into being of a state of life into this world, one that is constantly shifting and productive of new subject/individual positions. (p. 95)

Much is to be gained from this idea moving beyond the fixed positioning of other.

Although it is not my intention to reiterate inequalities and tensions from the dominant ablist viewpoint, I think it is important to acknowledge how labels in society are still prevalent and often position individuals on the margins. They take the form of binary distinctions-dualisms: abled/disabled, disabled /non-disabled, 
fit/frail, normal/abnormal, valid/invalid and classical/grotesque (Kuppers, 2003). "Notions of in-between spaces ... can problematize, challenge and offer an alternative to the dichotomies of binary opposition. Bodies and subjects can be considered to be 'in-between' because of a range of ambivalences that are inherent in their construction" (Briginshaw, 2001, p. 14). This statement has much to offer in that bodies are not easily contained and compartmentalised; they are messy, uncontrollable, bleed at the seams and resist being boxed in by labels and binary oppositions. Through their own practice many individuals, and the abovementioned dance companies frequently, butt up against these binaries by bringing to the 'stage' different bodies challenging the traditional notions of the dancing body. By representing alternative discourses in dance through performative, Albright (1997) argues these dancers may be able to exercise resistive power, which problematizes dominant and ableist discourses of what it means to be a dancer. Yes, there have been shifts through the opening up of spaces for different forms of embodiment within dance, challenging the dominant paradigms of western dance performance. However I agree with Matos (2008) who warns that dancers with disabilities are not necessarily free from stereotypes. "Stereotypes may subliminally or explicitly present a person with disability as a heroic figure who is in an endless quest to attain the paradigm of normality and who is this subject to comparison" (p. 81).

\section{Integrated Dance}

Benjamin (2001) argues that integration is about putting the divided parts (of society or ourselves) back in touch with each other. Furthermore he contests that “integration has no natural or linguistic association with 'disability' and we should resist any tendency to use and think of these as if they were in some way symbiotic.... When I use the word integration, it is an acknowledgement that existing 'exclusive' vision of dance is incomplete and in need of reform" (p. 14). Some years later in 2010, Benjamin states that being integrated is about "being in touch" and changing the larger picture, and he also asserts "as an aim or a methodology it still has much to offer" (p. 115). Other definitions are that integrated dance can be defined as people with different forms of embodiment, including disability (Kuppers, 2011), and dancer David Toole (2012) refers to integrated dance as both able-bodied and disabled dancers performing together. Using the definitions above, the two clips selected would certainly fit under integrated dance. 


\section{Limitations}

Time constraints proved to be a limiting factor in the discussion within the context of conference presentations. The shortfall of this was that the time for discussions, unpacking issues, delving deeper and engaging in sharing conversations with the whole group was limited. It could also be argued that this was more akin to a pilot project. However, this meant that the feedback I was party to was limited and was mainly focused on the dancers with different embodiments, which could be seen as a bias. In hindsight, clearly I was trying to cover too much complexity in the short space of time available.

\section{Responses and Discussions}

The responses from conference participants to this task varied. I witnessed some groups in deep discussion, clearly engaged with the provocations, who commented that there was not enough time to continue their conversations. A few were open to discussing their noticings with the whole group, but most felt safer communicating in small groups only. Full disclosure to the whole group within this setting was clearly difficult and challenged my agenda. However, I did notice that individuals at a conference with a 'culturally responsive' theme were far more open to disclosure than those in a dance conference so perhaps the conference context has a large bearing.

Was it enough to have promoted conversations or should they be analysed, shifted through, reconstituted and reinscribed on the page for all to read? It may be argued that drawing attention to some of the challenges and promoting small group discussions on embracing dancing difference may mean that, in future, individual lenses are broadened and may shift with the exposure to new work, thereby not remaining cemented in one narrow aesthetic.

However, I got the impression that some participants felt that there was nothing to discuss and assumed that everyone else was of the same opinion. This response troubled me and raised the following question: how do individuals with a variety of viewpoints and experience engage in conversations that recognise differing journeys through uneven terrain without opting out or shutting down? I would suggest that at any one moment viewing shifts and is not fixed nor static, allowing for multiple meanings and noticings that shift and slide as you witness the dance. However, it is very important to provide safe and ethical conditions for verbal disclosures. 
In one of the presentations I was challenged at the outset for using the word disabled. Terms, labels and definitions within this area are hugely problematic as alluded to above and working in this field, I have had my own struggles traversing this minefield and knowing when to use what term. I replied by acknowledging that this was contested and tricky and that I had asked several individuals working and theorising in this field for their responses to this very issue and that they were accepting of a number of different labels. Although I felt I was on solid ground with this explanation, now I am left wondering. Did I answer the challenge of using the word disabled or did I just reinforce ableist positions of power? I begin to doubtthis is very slippery territory full of potholes and the more I interrogate, the more I slip and slide.

Several participants verbally commented on David's dancing, describing it as fluid, strong and tender. In addition, they added that they were engaged with noticing the dancing and not the fact that David has no legs. Through his dancing David has pushed the traditional aesthetic of who can be a dancer and what a dancer should look like and how they move. This caption underneath the YouTube clip illustrates this:

David Toole of Candoco Dance Company compels attention. Propped on his hands, head lowered between his powerful shoulders, his gaze has a burning intensity. He disappears below the waist, unburdened by legs: his arms are his means of locomotion and of dancing, with or without a wheelchair.

Toole's abilities as a dancer have consistently caught viewers' attention, as Albright commented in 1997. Furthermore Albright (1997) suggests that "male disabled dancers evolve the virtuosic technically amazing body (even wthout legs)" (p. 76). Was David's dancing redefining the term virtuosity and could we apply Davies' (2008) comments: “Disabled dancers claim territory and status in a mainstream culture that finds new ways to see their work" (p. 53)? Respondents also noticed the way both dancers in this duet weaved in and out, over and under one another, foregrounding the relationship between the two dancers. Perhaps the two strong performers in this duet transcend physical difference?

In the duet To Color Me Different, choreographer Alex Ketley in collaboration with poet Carol Snow creates a tidal wave of engaging momentum that is described by Allah Ulrich as "a ferocious love duet ... both primal and oddly romantic" (http://axisdance.org/performance/our-repertory/). 
During this duet Rodney Bell stays in his wheelchair. Bell spins, balances, supports, moves backwards, changes speed, pauses, tilts, tips and leans. A discussion arose whereby one conference participant saw the wheelchair as a device, a prop or functional device to facilitate moving from one place to another, not a part of the dancer and his/her embodiment. They further commented that if Bell had not used his chair, like Toole in the first clip, they would have seen Rodney Bell the dancer not Rodney Bell the wheelchair user.

Embracing difference provides for opportunity to embrace bodies differently. How does the tension between people dancing differently and people dancing play out in these viewings? Much has been done to encourage this debate through sharing online media. These initial research forays with conference participants into this area offer further potential for deeper conversations and the development of ethical and safe ways for verbal disclosure to occur with respect and integrity without compromise.

Setting up conditions for disclosure is difficult, especially when the conversations are directly related to privilege and power imbalances. However, by exposing viewers to different dancing bodies it can be argued that challenge to the dominant aesthetics is raised with who dances and how they dance, and these challenges are brought to the fore. Further questions worthy of consideration are:

- What happens when gender issues are brought to the fore during these discussions?

- What might you see differently in the viewing if the dancers used crutches or other devices?

- How would having choreographers with a variety of embodiments further rupture the dominant aesthetics and change the viewing responses?

Complex relationships between viewers, performers, choreographers and the cultural context the works are viewed in create web-like relations. Permeating this web is the viewer's cultural background. The aim of these tasks within the conference presentation was to challenge how we view dance work. However, it must be stated that there is as much onus on the choreographer and the decisions they make, as there is on the viewer and the choices they make.

\section{Concluding comments}

In teaching and facilitating dance education, I regularly expose my students to a wealth and range of dance, which challenges their preconceptions. After watching a work by Touch Compass dance company, I question the students about what was 
significant or different. I note that there is often an uneasy silence, followed by a variety of noticing-particularly that there are performers with a disability. They never mention other performers. This seems to support Kuppers' (2003) assertion about the hyper-visibility of disabled performers. The intention of showing these clips to my students was to challenge and widen their view about who can dance and to expose them to a range of dance works within New Zealand. At this point I also inform them that Touch Compass's motto is "Dancing beyond difference". Many of my graduate student teacher trainees later report that they did not know or had not considered that individuals with a disability could dance. For many students such clips challenge their notions of who can dance and open up further possibilities, especially in relation to classroom practice. These students make the connection to the importance of getting all children in their classes, with or without a disability, dancing to their full potential.

With the explosion of dance clips on YouTube, the potential to further challenge assumptions through a range of edgy dance examples and movement possibilities are numerous. Within my teaching and research, I have a responsibility to set up ways that rich dialogue can happen around these viewings, being inclusive of tensions and dominant viewpoints that may arise. In writing this article I feel as though I have journeyed through very uneven terrain where rocky outcrops force me to look for other ways. There are few signposts, no maps or end points. However, I will continue to embrace the possibilities that the ever-changing technological world offers in relation to challenging a dominant dance aesthetic and the 'legitimate' dancing body and moving to embracing different forms of embodiment.

“The world’s terrain shimmers into ambiguity.” (Kuppers, 2011, p. 108)

\section{References}

Albright, A. C. (1997). Choreographing difference. Middletown, CT: Wesleyan University Press.

Albright, A. C. 2001). Strategic Abilities: Negotiating the Disabled Body in Dance. In Dils, A., \& Albright, A. C. (Eds.), Moving cultures/dancing cultures: A dance history reader. Middletown, (p.56-66). CT: Wesleyan University Press.

Benjamin, A. (2001). Making an entrance: Theory and practice for disabled and nondisabled dancers. London, England: Routledge.

Benjamin, A. (2010).Cabbages and kings: Disability, dance and some timely considerations. In A. Carter \& J. O'Shea (Eds.), The Routledge dance studies reader (2nd ed., p. 111121). Abingdon, England: Routledge

Briginshaw, V. (2001). Dance, space and subjectivity. Basingstoke, England: Palgrave.

Cheesman, S. (2001). Sydney 2000 Olympic Arts Festival-A Mixed Bag. Tirairaka, August, 20. 
Cheesman, S. (2011). A dance teacher's dialogue on working within disabled/non-disabled engagement in dance. The International Journal of the Arts in Society, 6(3), 321330.

Dandeker, C. (2007). A compelling combination. Animated, Spring, 5-7.

Davies, T. (2008). Mobility: AXIS dancers push the boundaries of access. Text and Performance Quarterly, 28, 43-63.

Irving, H., \& Giles, A. (2011). A dance revolution? Responding to dominant discourses in contemporary integrated dance. Leisure/Loisir, 35(4), 371-389.

Kuppers, P. (2003). Disability and contemporary performance: Bodies on edge. New York, NY: Routledge.

Kuppers, P. (2011). Disability culture and community performance: Find a strange and twisted shape. New York, NY: Palgrave.

Matos, L. (2008). Writing in the flesh: Body, identity, disability and difference. In S. Shapiro (Ed.), Dance in a world of change: Reflections of globilization and cultural differences (pp. 71-91). Champaign, IL: Human Kinetics.

Sandahl, C., \& Auslander, P. (2005). Bodies in commotion: Disability \& performance. Ann Arbor: University of Michigan Press.

Toole, D. (2012). David Toole interview on Challenging Dance on BBC Breakfast. http://www.bbc.co.uk/news/entertainment-arts-17892644

Whatley, S. (2007). Dance and disability: The dancer, the viewer and the presumption of difference. Research in Dance Education, 8(1), 5-25. doi:10.1080/14637890701272639 